\title{
Late Maternal Hypotension after Administration of a Mini- Dose of Clonidine Added to Epidural Analgesia for Labor
}

\author{
Adriano Bechara de Souza Hobaika ${ }^{1 *}$, Maurilio da Cruz Trigueiro ${ }^{2}$ and Vinicius \\ Pereira de Souza ${ }^{1}$ \\ ${ }^{1}$ Department of Anesthesiology, Mater Dei Hospital, Brazil \\ ${ }^{2}$ Department of Obstetrics, Mater Dei Hospital, Brazil
}

Received: November 27, 2013; Accepted: February 17, 2014, Published: February 19, 2014

*Corresponding author: Adriano Bechara de Souza Hobaika, Master of Science in Medicine, Department of Anesthesiology, Mater Dei Hospital, $R$ Des Jorge Fontana 336/1701, Belvedere. BH-MG, Brazil, Tel: 30-320-670; E-mail: hobaika@globo.com

Keywords: Clonidine; Maternal hypotension; Labour analgesia

\section{Letter to Editor}

Clonidine is an alpha-2-agonist that has been used in perioperative medicine for several purposes: premedication, neuraxial analgesia adjuvant to promote hemodynamic stability, anti-sialagogue and treatment of per-operative shivering. The duration of action of this drug is approximately 12 hours. Recently, anesthesiologists are being interested in the use of clonidine for labor analgesia, both as intrathecal or epidural. Primigravida, 25 years old, 38 weeks of pregnancy, requested analgesia for vaginal delivery with $3 \mathrm{~cm}$ cervical dilatation. After venous puncture, epidural interspace L4-L5 was punctured, with the loss of resistance technique. Then, $20 \mathrm{ml}$ of bupivacaine $0.065 \%$ with sufentanil $(10 \mu \mathrm{g})$ and clonidine $(37.5 \mu \mathrm{g})$ was administered. The catheter was introduced $5 \mathrm{~cm}$ into the epidural space. After four hours, with cervical dilatation of $6 \mathrm{~cm}$, it was necessary to administer another dose and $12 \mathrm{ml}$ bupivacaine $0.065 \%$ was administered. After two hours it was necessary to give another shot of $12 \mathrm{ml}$ of $0.08 \%$ bupivacaine. After 8 hours of labor, one female healthy baby (Apgar 9/9) was born. The procedure was uneventful, and blood loss was usual. Half an hour later, the patient complained of feeling dizzy, presenting a heart rate of $52 \mathrm{bpm}$ and blood pressure=83/35. Hypotension was treated immediately with ephedrine $20 \mathrm{mg}$. She was transferred to the post-anesthetic room stable, where after an hour the patient presented hypotension again and $51 \mathrm{bpm}$, with profuse sweating and cold extremities. A dose of $35 \mathrm{mg}$ of ephedrine, volume expansion with $500 \mathrm{ml}$ of hydroxyethyl starch $6 \%$ and $1000 \mathrm{ml}$ of saline was infused with good clinical response. The use of clonidine for epidural labor analgesia has been extensively studied in the last decade, although not with doses below $60 \mu \mathrm{g}$. The studies are controversial and performed with small patient sampling. Advantages of adding clonidine are reducing the mass of local anesthetics and opioids and their adverse effects. Disadvantages include a higher risk of maternal hypotension and bradycardia, sedation and neonatal behavioral change. Maternal hypotension is the most common adverse effect and may reduce uteroplacental blood flow. In a study by Van de Velde et al. (2009) clonidine $75 \mu \mathrm{g}$ associated with neostigmine $500 \mathrm{mg}$ prolonged analgesia and there was a decrease in the mass of epidural local anesthetic [1]. Epidural clonidine at a dose of $60 \mu \mathrm{g}$, added to bupivacaine, increased the duration of analgesia in $30 \%$, with no major adverse effects when compared to bupivacaine without additives [2]. Studies with larger epidural clonidine (120-150 $\mu \mathrm{g})$ doses showed significant adverse effects such as sedation, hypotension, bradycardia and fetal heart rate abnormalities [3-6]. In one study, lower doses (30 $\mu \mathrm{g})$ showed no significant benefits [7]. There is still no consensus about the use of epidural clonidine dosage. Suggested safe dosages range between $60 \mu \mathrm{g}$ and $75 \mu \mathrm{g}$. Studies on epidural doses above $60 \mu$ gare almost inexistent. Therefore, possibly, in specific cases, patients would benefit from receiving a mini dose of the drug like: difficulty to control the pain, intolerance to opioids or anxiety. This patient showed a significant hypotension, delayed and abruptly after 8 hours and 9 hours of its administration although there were no signals of relevant blood loss or peripartum cardiac disease.

\section{Acknowledgement}

Supported by Mater Dei Hospital, Brazil.

\section{References}

1. Van de Velde M, Berends N, Kumar A, Devroe S, Devlieger R, et al. (2009) Effects of epidural clonidine and neostigmine following intrathecal labour analgesia: a randomised, double-blind, placebocontrolled trial. Int J Obstet Anesth 18: 207-214.

2. Syal K, Dogra RK, Ohri A, Chauhan G, Goel A (2011) Epidural labour analgesia using Bupivacaine and Clonidine. J Anaesthesiol Clin Pharmacol 27: 87-90.

3. Cigarini I, Kaba A, Bonnet F, Brohon E, Dutz F, et al. (1995) Epidural clonidine combined with bupivacaine for analgesia in labor. Effects on mother and neonate. Reg Anesth 20(2): 113-120.

4. O'Meara ME, Gin T (1993) Comparison of $0.125 \%$ bupivacaine with $0.125 \%$ bupivacaine and clonidine as extradural analgesia in the first stage of labour. Br J Anaesth 71(5): 651-656.

5. Landau R, Schiffer E, Morales M, Savoldelli G, Kern C (2002) The dose 
sparing effect of clonidine added to ropivacaine for labour epidural analgesia. Anaesth Analg 95(3): 728-734.

6. Dewandre PY, Decurninge V, Bonhomme V, Hans P, Brichant JF (2010) Side effects of the addition of clonidine 75 microg or sufentanil 5 microg to $0.2 \%$ ropivacaine for labour epidural analgesia. Int J Obstet Anesth 19(2): 149-154.

7. Le Polain B, De Kock M, Scholtes JL, Van Lierde M (1993) Clonidine combined with sufentanil and bupivacaine with adrenaline for obstetric analgesia. Br J Anaesth 71(5): 657-660. 